\title{
PENDAMPINGAN PENGELOLAAN WEBSITE SEKOLAH DAN PELATIHAN PEMBUATAN SOAL UJIAN ONLINE DI SMA MUHAMMADIYAH 5 JATEN KARANGANYAR
}

\author{
Oleh: \\ Ardhi Wijayanto ${ }^{1}$, Wisnu Widiarto ${ }^{2}$ \\ 1,2Program Studi Informatika \\ Universitas Sebelas Maret \\ ardhi.wijayanto@staff.uns.ac.id
}

\begin{abstract}
Abstrak
SMA Muhammadiyah 5 Jaten Karanganyar menghadapi tantangan yaitu pemanfaatan teknologi informasi (TI). Pembelajaran secara tatap muka dalam kondisi pandemi belum memungkinkan sehingga pemanfaatan $\mathrm{TI}$ menjadi ujung tombak penyebaran informasi dan sarana kegiatan belajar mengajar. Masalah yang dihadapi SMA Muhammadiyah 5 Jaten Karanganyar adalah belum tersedianya website sekolah yang memuat informasi yang diperlukan bagi peserta didik dan belum maksimalnya pemanfaatan TI untuk membantu kegiatan belajar mengajar. Berdasarkan permasalahan pada mitra, diusulkan pembuatan sebuah website sekolah dan pelatihan pembuatan soal ujian online untuk mendukung pembelajaran jarak jauh. Website sekolah akan menggunakan domain sch.id yang merupakan domain resmi instansi sekolah di Indonesia. Adapun online tools yang dilatihkan untuk membut soal ujian online adalah Microsoft Forms dan Quizziz. Pelatihan pembuatan soal ujian online memberikan bekal bagi para guru untuk mengatasi tantangan di masa pandemi yang mengharuskan kegiatan belajar mengajar beralih menjadi pembelajaran jarak jauh. Kegiatan pengabdian yang telah dilakukan ini memberi manfaat bagi SMA Muhammadiyah 5 Jaten Karanganyar sebagai mitra pengabdian untuk meningkatkan branding dan memberi nilai tambah penilaian kualitas sekolah melalui adanya web sekolah. Diharapkan kompetensi para guru semakin meningkat dan merata dalam memanfaatkan TI untuk meningkatkan kualitas kegiatan belajar mengajar dan mengatasi tantangan yang muncul akibat kondisi pandemi Covid-19.
\end{abstract}

Kata Kunci: website, $\mathrm{Tl}$, ujian online

\begin{abstract}
The utilization of Information Technology (IT) still become an issue for SMA Muhammadiyah 5 Jaten Karanganyar. Meanwhile, the pandemic condition forced teachers to improve IT utilization for supporting teaching and learning activities. SMA Muhammadiyah 5 Jaten Karanganyar face wo problems, first is the unavailibility of an official school website, and second problem is the inadequate use of IT to assist teaching and learning activities. Based on the problems faced by the partner, we propose to build a school website and held training to write online exam to support the distance learning. The school website will use the sch.id domain. The teachers trained to write online exam questions using are Microsoft Forms and Quizziz. The community service activities that have been carried out have benefited SMA Muhammadiyah 5 Jaten Karanganyar to increase their branding and provide added value in assessing the school quality. It is hoped that the competence of teachers will increase and be spread evenly in utilizing IT to improve the quality of teaching and learning activities and overcome the challenges that arise due to the conditions of the Covid19 pandemic.
\end{abstract}

Keywords: website, IT, online exam

\begin{abstract}
PENDAHULUAN
SMA Muhammadiyah 5 Jaten Karanganyar merupakan sekolah swasta dalam naungan yayasan perserikatan Muhammadiyah bidang pendidikan dan pengajaran. Sekolah ini berada di Kecamatan Jaten, Kabupaten Karanganyar, Provinsi Jawa Tengah. Sekolah yang memiliki 24 orang guru dan karyawan ini memiliki 92 orang siswa yang terbagi dalam 5 kelas dengan penjurusan ilmu sosial. SMA Muhammadiyah 5 Jaten Karanganyar juga merupakan sekolah inklusi yang memberi kesempatan menuntut ilmu
\end{abstract}

bagi siswa berkebutuhan khusus, sebanyak 3 orang siswa disabilitas tuna netra bersekolah di sini. SMA Muhammadiyah 5 Jaten Karanganyar menampung siswa yang sebagian besar berasal dari keluarga menengah ke bawah. Setiap tahun jumlah siswa cukup bervariasi, pada tahun ajaran 2018/2019 terdapat 3 rombel siswa kelas XII, sementara kelas $X$ dan XII memiliki 2 rombel. Kemudian, di tahun ajaran berikutnya semua kelas masing-masing memiliki 2 rombel. Fasilitas untuk menunjang kegiatan belajar mengajar terus 
diusahakan oleh sekolah yang saat ini telah memiliki laboratorium bahasa dan komputer.

SMA Muhammadiyah 5 Jaten Karanganyar yang menjadi mitra pengabdian ini menghadapi tantangan, yaitu pemanfaatan teknologi informasi (TI), terutama ketika pandemi Covid-19 masih merebak. John Hopkins Coronavirus Resource Center mencatat jumlah kasus Covid-19 kumulatif di seluruh dunia sampai 4 November 2020 telah mencapai lebih dari 47 juta kasus, dengan 421.731 kasus diantaranya terjadi di Indonesia. Pembelajaran secara tatap muka belum memungkinkan sehingga TI menjadi ujung tombak penyebaran informasi dan sarana pembelajaran untuk peserta didik. Menurut Pakpahan (2020), pembelajaran daring menjadi solusi untuk memenuhi standar pendidikan dengan pemanfaatan TI. Masalah yang dihadapi SMA Muhammadiyah 5 Jaten Karanganyar adalah belum tersedianya website sekolah yang memuat informasi yang diperlukan bagi peserta didik dan belum maksimalnya pemanfaatan TI untuk membantu kegiatan belajar mengajar bagi para guru dan peserta didik.

Ketersediaan website sekolah menjadi sebuah hal yang wajib sebagai salah satu tolak ukur kualitas pendidikan di era digital. Demikian pula pemanfaatan $\mathrm{TI}$ untuk menunjang kegiatan belajar mengajar mutlak diperlukan guna mendukung kegiatan belajar jarak jauh sebagai konsekuensi dari pandemi Covid-19. Permasalahan yang sering dihadapi adalah jangkauan penyebaran informasi dari sekolah yang masih kurang luas, misalnya ketika ada kegiatan penerimaan siswa baru, calon pendaftar seringkali masih kurang jelas mengenai persyaratan pendaftaran karena informasi penerimaan siswa baru yang belum dapat diakses dari internet.

Dengan jumlah pengguna internet di Indonesia yang mencapai 175,4 juta orang (Kominfo, 2020), keberadaan website sekolah sangat penting. Menurut Utari (2013), website sekolah dapat dijadikan sebagai media humas untuk menampilkan image positif sekolah terkait profil maupun hubungannya dengan masyarakat. Kemudian dalam pembelajaran jarak jauh, kompetensi guru dalam memanfaatkan layanan TI belum merata. Penguasaan guru terhadap perangkat dan aplikasi TIK menjadi aspek yang sering mendapat perhatian untuk ditingkatkan (Batubara, 2017).

Berdasarkan gambaran umum kondisi sekolah, SMA Muhammadiyah 5 Jaten Karanganyar memiliki potensi untuk pengembangan institusi dengan menjaring lebih banyak peserta didik dan peningkatan kualitas sebagai sekolah inklusi yang mampu memberikan manfaat bagi masyarakat khususnya yang memiliki anak berkebutuhan khusus agar dapat merasakan pendidikan tingkat menengah. Untuk itu, dalam rangka pelaksanaan kegiatan penelitian dan pengabdian pada masyarakat yang didanai PNBP UNS pada periode tahun 2020, penulis bermaksud untuk memaparkan hasil pengabdian dalam bentuk pembuatan website sekolah dan pelatihan pembuatan soal ujian online untuk pembelajaran jarak jauh di SMA Muhammadiyah 5 Jaten Karanganyar

\section{METODE}

\section{A. Obyek Pengabdian}

Pengabdian dilakukan di SMA Muhammadiyah 5 Jaten Karanganyar untuk membuat website sekolah dan pelatihan pembuatan soal ujian online untuk mendukung kegiatan pembelajaran jarak jauh. Target pengabdian adalah operator $\mathrm{TI}$ sekolah yang diberi tugas untuk mengelola website serta para guru untuk pelatihan penggunaan tool untuk membuat soal ujian online.

\section{B. Masalah yang Dihadapi}

SMA Muhammadiyah 5 Jaten Karanganyar belum memiliki website sekolah yang memuat informasi untuk diakses siswa maupun masyarakat umum. Dengan adanya website sekolah, informasiinformasi mengenai sekolah dapat diupload untuk meningkatkan jangkauan akses informasi sehingga semakin banyak masyarakat yang mengenal profil sekolah. Semakin luasnya jangkauan informasi menjadi sangat penting nilainya bagi sebuah sekolah swasta misalnya untuk menjaring calon siswa baru yang lebih banyak. Oleh karena itu, perlu adanya sebuah website sekolah yang representatif.

Pemerataan kompetensi guru dalam pemanfaatan $\mathrm{TI}$ menjadi hal yang juga perlu diperhatikan. Pembelajaran jarak jauh yang dijalankan sekolah menjadikan penguasaan TI oleh guru memegang peranan yang sangat penting. Menurut Martini dkk (2017), penguasaan teknologi komputer oleh para guru saat ini mutlak diperlukan, salah satunya untuk memperkaya bentuk media pembelajaran. Saat ini guru-guru senior mengalami ketertinggalan dalam pemanfaatan layanan elearning. Beban guru kelas dan guru junior menjadi lebih berat sebagai konsekuensi dari kondisi tersebut. Untuk itu dirasa perlu untuk melakukan pelatihan guna meningkatkan kompetensi guru dalam melakukan pembelajaran jarak jauh dengan memanfaatkan sejumlah tool.

\section{Alternatif Pemecahan Masalah}

Berdasarkan permasalahan pada mitra, diusulkan pembuatan sebuah website sekolah dan pelatihan pembuatan soal ujian online untuk mendukung pembelajaran jarak jauh. Website sekolah akan menggunakan domain sch.id yang merupakan domain resmi instansi sekolah di Indonesia, sehingga diharapkan juga dapat meningkatkan penilaian akreditasi sekolah di masa mendatang. Adapun online tool yang dilatihkan untuk dimanfaatkan dalam kegiatan pembelajaran jarak jauh adalah Microsoft Forms dan Quizziz. Penggunaan online tool dimaksudkan untuk memperkaya variasi media pembelajaran, menurut Rosdiana dan Maulidha (2017) pengembangan media pembelajaran harus terus dilakukan agar siswa tidak merasa jenuh serta menumbuhkan rasa senang dalam belajar. 
HASIL DAN PEMBAHASAN

A. Tahapan Pelaksanaan Pengabdian

Pelaksanaan pengabdian di SMA

Muhammadiyah 5 Jaten Karanganyar meliputi sejumlah tahapan sebagai berikut:

1. Penyusunan dan analisis kebutuhan Kebutuhan mengenai website sekolah yang akan dibangun dikumpulkan melalui proses wawancara. Pihak sekolah menyediakan material yang ingin ditampilkan ke website dan kebutuhan mengenai tool untuk pembelajaran jarak jauh.

2. Instalasi website

Pada tahap ini dilakukan pemasangan website ke layanan web hosting dan konfigurasi domain.

3. Pelatihan pembuatan soal ujian online Selanjutnya adalah tahapan pelatihan pembuatan soal ujian online dengan menggunakan online tool, yaitu Microsoft Forms dan Quizziz untuk para guru oleh tim pengabdian.

\section{B. Metode Pendekatan yang Digunakan}

Pendekatan yang digunakan adalah pelatihan dan pendampingan. Pelatihan dilakukan pada pembangunan web sekolah untuk guru operator website terutama untuk menulis konten. Pelatihan juga dilakukan kepada guru untuk memanfaatkan Microsoft Forms dan Quizziz untuk mengadakan ujian secara online. Pendampingan dilakukan pada saat web sekolah sudah aktif dengan sasaran adalah operator TI sekolah agar dapat mengelola web dengan optimal.

\section{Partisipasi Mitra dalam Pelaksanaan} Program

Mitra pengabdian berpartisipasi menyediakan materi yang akan ditampilkan ke website sekolah, di antaranya foto-foto kegiatan sekolah, arsip data prestasi siswa, arsip kegiatan ekstrakurikuler, dan data pengumuman.

Pihak sekolah juga ikut berperan dalam proses evaluasi. Salah satu proses evaluasi yang dilakukan adalah untuk mengukur efektivitas website sekolah sebagai media promosi kegiatan penerimaan siswa baru. Sekolah memberikan data jumlah siswa yang diterima di tahun ajaran 2020/2021, selanjutnya akan dibandingkan datanya dengan jumlah siswa yang diterima di tahun sebelumnya.

\section{Evaluasi dan Keberlanjutan}

Evaluasi dilihat dari kemudahan akses informasi yang didapat dengan adanya web sekolah dan penguasaan guru terhadap tool Microsoft Forms dan Quizziz. Dampak dari adanya website sekolah juga dievaluasi, yaitu dari jumlah siswa yang diterima pada tahun ajaran baru. Sebelumnya telah dipasang materi pengumuman mengenai penerimaan siswa baru di web sekolah untuk kemudian dibagikan tautannya ke media sosial.
Berdasarkan data yang diberikan sekolah, pada tahun ajaran 2020/2021 terdapat peningkatan jumlah siswa baru sebesar $28 \%$ dari tahun ajaran sebelumnya. Seperti yang ditunjukkan pada Tabel 1, pada tahun ajaran 2019/2020 terdapat 65 siswa baru yang dibagi menjadi 2 kelas. Setelah adanya web sekolah, pada tahun ajaran 2020/2021 jumlah siswa baru meningkat menjadi 83 siswa yang dibagi menjadi 3 kelas.

Tabel 2. Jumlah siswa baru

\begin{tabular}{|c|c|}
\hline Tahun ajaran & Jumlah siswa baru \\
\hline $2019 / 2020$ & 65 \\
\hline $2020 / 2021$ & 83 \\
\hline
\end{tabular}

Keberlanjutan kegiatan pengabdian ini adalah data akses web sekolah dimanfaatkan untuk penelitian grup riset pada tahun berikutnya dengan topik website management. Pengelolaan web sekolah selanjutnya dilakukan oleh sekolah melalui operator TI sekolah.

\section{E. Implementasi Website Sekolah}

Kebutuhan terkait web sekolah antara lain lokasi hosting, alamat domain, dan materi yang akan ditulis di web dikumpulkan melalui wawancara. Wawancara dilakukan dengan guru yang menjadi operator data sekolah, proses ini dilakukan melalui chat Whatsapp. Didapatkan alamat domain yang akan digunakan adalah http://smamuh5kra.sch.id/ dengan menggunakan hosting selama 4 tahun.

Website dibangun menggunakan CMS Wordpress dengan menambahkan theme berbayar. Pada web sekolah tersebut ditampilkan informasi mengenai profil sekolah, visi misi sekolah, dan sejarah sekolah seperti ditunjukkan pada Gambar 1 dan Gambar 2.

\section{PROFIL}
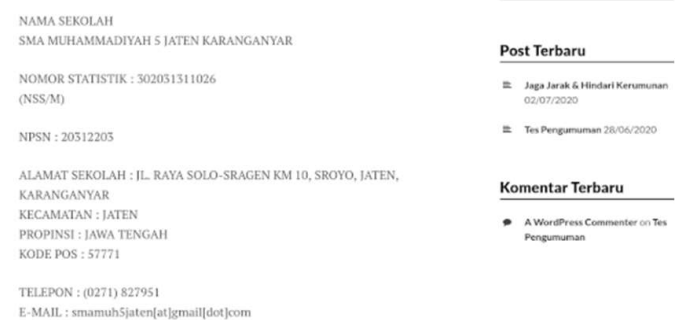

Gambar 1. Halaman web yang memuat profil sekolah 
Jaga Jarak \& Hindari Kerumunan
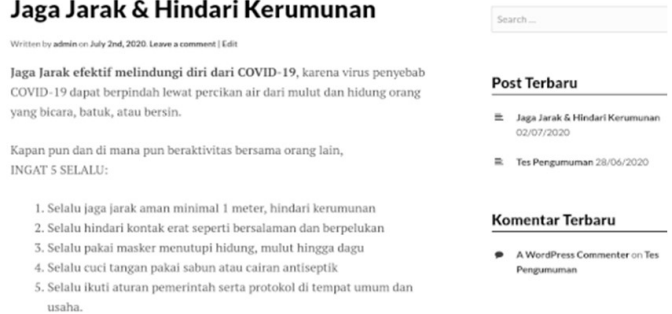

Gambar 2. Halaman web yang memuat berita

\section{F. Pelatihan Penggunaan Microsoft Forms} dan Quizziz

Kegiatan ini diikuti oleh para guru SMA Muhammadiyah 5 Jaten Karanganyar yang dilaksanakan dengan menerapkan protokol kesehatan. Peserta pelatihan diberi materi mengenai pemanfaatan Microsoft Forms dan Quizziz untuk membuat soal ujian online. Kuis yang dibuat dengan quizziz hasilnya ditunjukkan pada Gambar 3..

Gambar 4 menunjukkan peserta pelatihan yang diikuti oleh enam orang guru. Setelah kegiatan pelatihan, peserta bersama dengan tim pengabdian mengambil foto bersama pada Gambar 5 .

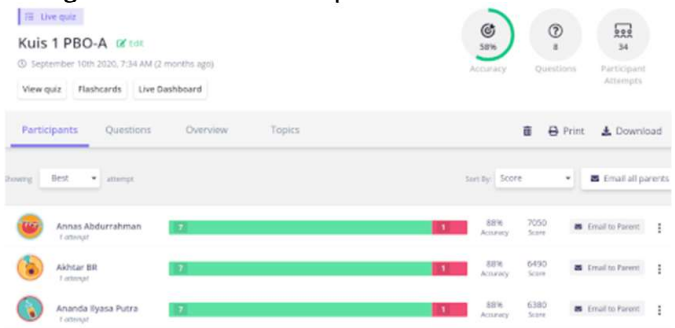

Gambar 3. Hasil ujian online yang dibuat menggunakan Quizziz

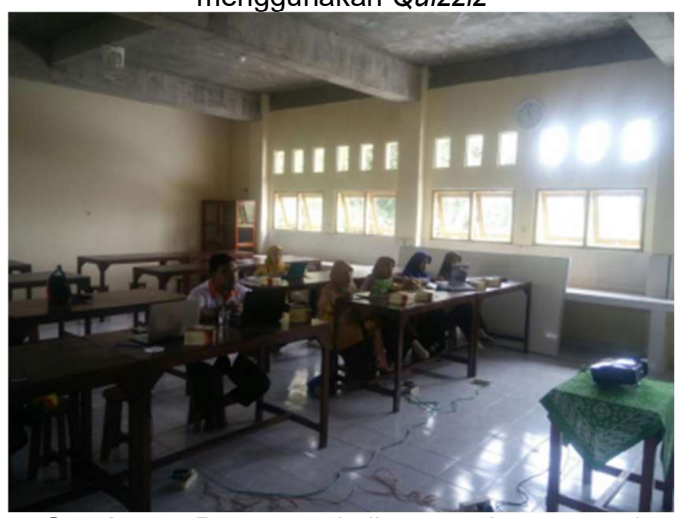

Gambar 4. Peserta pelatihan pembuatan soal ujian online

Gambar 5. Peserta pelatihan pembuatan soal ujian online

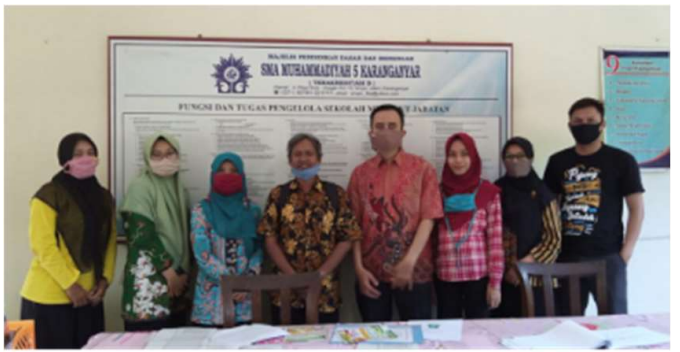

\section{SIMPULAN DAN SARAN}

\section{Simpulan}

Kegiatan pengabdian yang telah dilakukan ini memberi manfaat bagi SMA Muhammadiyah 5 Jaten Karanganyar sebagai mitra pengabdian untuk meningkatkan branding dan memberi nilai tambah penilaian kualitas sekolah. Salah satu indikatornya adalah adanya peningkatan jumlah siswa baru yang mendaftar ke sekolah setelah melihat informasi yang diposting melalui web sekolah.

Pelatihan pembuatan kuis online meningkatkan kemampuan penguasaan teknologi informasi bagi guru, guru merasa lebih praktis dalam membuat evaluasi karena kuis online dapat dinilai secara otomatis berdasarkan jawaban dari siswa.

\section{Saran}

Kegiatan PkM yang dilakukan di SMA Muhammadiyah 5 Jaten Karanganyar ditindaklanjuti di tahun berikutnya. Website sekolah yang sudah dibangun dapat dimanfaatkan untuk kegiatan penelitian misalnya dengan mengolah data akses web sekolah untuk penelitian dengan topik website management. Pengelolaan web sekolah selanjutnya dilakukan oleh sekolah melalui operator TI sekolah.

\section{DAFTAR PUSTAKA}

Johns Hopkins Coronavirus Resource Center, diakses 4 November 2020 dari https://coronavirus.jhu.edu/map.html

Batubara, D.S. (2017). Kompetensi Teknologi Informasi dan Komunikasi Guru SD/MI (Potret, Faktor-faktor, dan Upaya Meningkatkannya). MUALLIMUNA: Jurnal Madrasah Ibtidaiyah, Vol. 3, No. 1, 48-65.

Martini, Qosyim A., dan Purnomo, A.R. ( 2017). Pendampingan Pembuatan Media Pembelajaran Berbentuk Flash-like Powerpoint bagi Guru IPA SMP di Kabupaten Jombang. Jurnal ABDI Vol. 2, No. 2, 66-71.

Kominfo. (2020). Dirjen PPI: Pengguna Seluler dan Internet Potensial Jadi Pasar Layanan Pos. Diakses 27 Oktober 2020,

Rosdiana, L., Maulidha F., A. N. (2017) Respon Guru dalam Pendampingan Pembuatan Media Permainan. Jurnal ABDI Vol. 2, No. 2, 83-86 